\title{
Associations between parent and child pain and functioning in a pediatric chronic pain sample: A mixed methods approach
}

\author{
Subhadra Evans, PhD, Marcia Meldrum, PhD, Jennie Cl Tsao, PhD, Rebecca Fraynt, MA, \\ and Lonnie K Zeltzer, MD \\ Pediatric Pain Program, Department of Pediatrics, David Geffen School of Medicine, University of \\ California Los Angeles, Los Angeles, United States of America
}

\begin{abstract}
This study employed a mixed-method design to test sex-specific parent-child pain associations. Subjects were 179 chronic pain patients aged $11-19$ years (mean $=14.34 ; 72 \%$ female) presenting for treatment at a multidisciplinary, tertiary clinic. Mothers and children completed questionnaires prior to their clinic visit, including measures of children's pain, functioning and psychological characteristics. Mothers also reported on their own pain and psychological functioning. Interviews were conducted with a sub-sample of 34 mothers and children prior to the clinic visit and analyzed using a grounded theory approach. The quantitative data suggest stronger mother-daughter than mother-son pain relationships. The qualitative data suggest that girls' pain and pain-related disability is related to an overly enmeshed mother-daughter relationship and the presence of maternal models of pain, while boys' pain and disability is linked to male pain models and criticism and to maternal worry and solicitousness. Boys and girls appear to have developmentally incongruous levels of autonomy and conformity to maternal expectations. The mixed-method data suggest distinct trajectories through which mother and father involvement may be linked to chronic pain in adolescent boys and girls.
\end{abstract}

\section{Keywords}

Sex differences; parent-child relationships; chronic pain

\section{INTRODUCTION}

An emerging literature has documented associations between parental behaviors and children's pain. Trans-generational pain relationships have been noted within the laboratory and the clinic. Such studies have shown that children with chronic pain are more likely to have parents with chronic pain (1-4) and that parents with chronic pain report increased pain sensitivity in their children $(2,5)$. Important etiological factors are likely to include the parent's pain and psychological history as well as family functioning processes $(6,7)$.

Family predictors of child pain have been examined in several chronic pain samples, including juvenile arthritis and parent pain history (1), where higher levels of current parent bodily pain were correlated with increased child arthritis pain. Research has also shown relationships between child fibromyalgia and multiple chronic pain conditions in parents, 8 child-mother abdominal pain (9) and child -parent headache and migraine (2-4). Laboratory studies have demonstrated sex-specific influences of parental behavior on children's pain

Correspondence: Subhadra Evans, PhD, Pediatric Pain Program, Department of Pediatrics, David Geffen School of Medicine at UCLA, MDCC 22-464, 10833 Le Conte Ave 90024, United States. Tel: 310-794-2936; Fax: 310-794-2954;

suevans@mednet.ucla.edu. 
responses. Chambers compared the effect of mothers' pain-promoting behavior on boys' versus girls' cold pressor pain and found a relationship between maternal behavior and girls' cold pressor pain responses, which did not hold for boys (10). Another study examining the link between family pain and young adults' laboratory pain highlights significant sex differences in familial pain relationships. A positive family history of pain was related to increased pain episodes and sensitivity to experimental thermal pain in females, but not in males (11). Moreover, laboratory work with a healthy sample of children demonstrated sex differences in the relationship between maternal and child pain, with child reports of maternal bodily pain more strongly related to daughters' than to sons' bodily and laboratory pain sensitivity (12).

Sex-specific family relationships have largely been excluded from pediatric pain studies, despite the finding that females appear to be more sensitive to familial pain models than are males (13). In one study exploring parental physical illness as a risk factor for children's psychosocial adjustment, adolescent girls' and boys' functioning was adversely affected when the respective same-sex parent had a serious physical illness (14). This study did not include parent or child pain, but it is possible that similar sex-specific relationships operate for pain. Consistent with gender role expectations and social learning theory in which the salience of pain models may hinge on identification to models, it is possible that mothers play a greater role in daughters' than in sons' pain, while fathers play a greater role in sons' than daughters' pain. Researchers have only recently focused on the role of maternal behavior in children's pain, but fathers remain largely absent from investigations.

In the present study, we used a mixed-methods approach to examine sex-specific parentchild relationships in the development of chronic pain in preadolescent and adolescent children. First, on the basis of a large quantitative database, explored links between parent and child pain as a function of parent and child sex. Second, we used qualitative methodology to document the experiences of children with chronic pain and their mothers. Interviews were analyzed to explore potential mechanisms underlying the relationship between parental behaviors and children's functioning. To our knowledge, this is the first time that sex-specific parent-child pain relationships in a clinical sample of children with chronic pain have been explored. We hypothesized significant positive associations between maternal pain and functioning and children's pain and functioning status. Specifically, we expected the qualitative and quantitative data would reveal stronger associations for motherdaughter than mother-son pain relationships.

\section{METHODS}

Subjects were chronic pain patients presenting for treatment at a multidisciplinary, tertiary clinic specializing in pediatric chronic pain. The quantitative data were derived from 229 families who agreed to take part in a study examining outcomes in pediatric chronic pain (details of the qualitative sample are discussed below). The quantitative analyses focused on relationships between mothers and children, thus quantitative data from other family members who also attended the clinic with the child, including fathers $(\mathrm{n}=13)$ and adopted or foster mothers $(\mathrm{n}=11)$, were excluded. For an additional 17 cases, relationship data were missing. For another nine subjects, mothers did not complete questionnaires about themselves, leaving a final sample of 179 mother-child pairs in the quantitative sample. There were no significant differences between children in the final sample and the original sample on demographic variables such as age and sex.

Children and adolescents in the final quantitative sample ranged in age from 11 to 19 years $($ mean $=14.34$ years, $\mathrm{SD}=2.55)$. There were 128 girls $(72 \%)$ and 51 boys $(29 \%)$. The majority of children were Caucasian (69\%), although a number of ethnic minorities were 
represented, including Hispanic (13\%), African American (4\%), Asian (1\%), Native American (2\%) and other minorities (11\%). A subset of 72 families were administered the Functional Disability Inventory (FDI), items about the child's current level of pain, and parents were administered the Anxiety Sensitivity inventory (ASI). This subset did not significantly differ from the overall group on child age, sex, ethnicity or pain duration.

\section{Procedure and measures: Quantitative data}

Procedures for the administration of the questionnaire measures for the quantitative analyses are described in detail elsewhere $(15,16)$. In brief, before children's initial clinic visit, two questionnaire packets, one for the child and one for a parent, were mailed to the home. Children and parents were instructed to complete the questionnaires separately without consulting one another. Families were asked to bring the questionnaires with them to the initial clinic appointment. The time elapsed between questionnaire completion and the initial clinic appointment ranged from $2-175$ days (mean $=45.8$ days; $\mathrm{SD}=38.9$ ). During the appointment, a research assistant first reviewed the questionnaires to address missing or ambiguous responses (e.g., duplicate responses to the same item); clinicians later also reviewed the responses and asked parents and children to clarify responses that were unclear. The questionnaires assessed demographic and general health information including measures of the child's pain, anxiety and functioning. Only those measures relevant to the current study are discussed below.

Study procedures were approved by the UCLA Institutional Review Board (IRB). IRBapproved written informed consent forms were completed by parents, and children provided written assent.

Clinical information regarding duration of pain symptoms, and number and type of pain diagnoses was obtained from patients' medical records via chart review. A standard evaluation form was used to assess all new patients, so that the same group of questions was asked of each patient.

\section{Questionnaires completed by mothers}

Demographic Information Questionnaire-An author-developed demographic information questionnaire was completed by mothers, assessing information such as child age, sex, and race/ethnicity. Mothers were also asked about their own pain symptoms. In version 1 , mothers were asked to list any pain problems, in version 2 , they were asked to check off specific categories (e.g., head pain etc). Maternal pain reports were categorized by location for both versions of the demographic questionnaire. Mothers were also asked about the presence of pain in the secondary caregiver. All mothers listed the father or step-father as the secondary caregiver.

Children's Somatization Inventory (CSI) - Parent Report-The CSI contains 35 psychophysiological symptoms rated on 5-point scales: $0=$ not at all; $1=$ a little; $2=$ somewhat; $3=$ pretty much; and $4=$ very much. Mothers indicated the extent to which their children experienced each symptom over the past two weeks. Symptoms include gastrointestinal (e.g. "nausea/upset stomach"), pseudoneurological (e.g. "seizures"), cardiovascular (e.g. "heart beats too fast"), and pain (e.g. "pain in arms or legs") complaints. Total score can be computed by summing the score across all items. Higher scores indicate higher levels of somatic complaints. Internal consistency has been shown at 0.92 for healthy samples, and test-retest reliability at $0.66(\mathrm{P}=.001)(17)$.

Functional Disability Inventory (FDI) - Parent report-The FDI is a 14-item questionnaire measuring children's difficulty in physical and psychosocial functioning due 
to their physical health during the past two weeks. Mothers rated the severity of their child's functional disability in daily activities including walking, chores, social activities, eating and sleeping. Respondents rate the level of difficulty their child has performing each of the items and total scores are computed by summing the ratings for each item. Higher scores indicate greater disability. The FDI has been documented as valid, stable, and sensitive to change (18).

Child Pain Intensity-Mothers were asked to rate their child's current pain on a 10-cm Visual Analogue Scale (VAS) representing a continuum from no pain to worst pain possible. The VAS has been widely used as a reliable and valid measure of pain intensity with children (19).

Symptom Checklist-90R (SCL-90)—Mothers completed this widely used instrument of psychological functioning. The checklist measures nine dimensions, and only the depression, somatization, and anxiety sub-scales were used in the present study. Items are scored on a 5-point scale of stress ranging from 'not at all' to 'extremely.' Good internal consistency (a range $=.77-.90$ ) and adequate test-retest reliability (range $.68-.83$ over 10 weeks) have been reported (20).

The Anxiety Sensitivity Index (ASI) (21)—a 1 6-item measure of the tendency to interpret physical sensations as harmful, asks participants to indicate on a 5-point scale (very little, a little, some, much, very much) the degree to which each statement is true. The ASI has been shown to have adequate internal consistency $(\mathrm{a}=.82)$ and high test-retest reliability (.71 over 3 years) (22).

\section{Child self-report questionnaires}

Child Pain Intensity-Children were asked to rate their current pain on a 10-cm Visual Analogue Scale (VAS) representing a continuum from no pain to worst pain possible.

Child Depression Inventory (CDI) (23)—is a 27-item instrument that assesses symptoms of depression, ranging from 0 (absence of symptom) to 2 (definite symptom). The CDI has been demonstrated to have good internal consistency, adequate test-retest reliability and validity (24).

Children's Anxiety Sensitivity Inventory (CASI)—This is an 18-item scale that assesses the tendency to view anxiety-related bodily sensations as dangerous (eg, "Unusual feelings in my body scare me;" "It scares me when I have trouble getting my breath"). It represents a downward extension of the adult measure, the Anxiety Sensitivity Index (ASI) (21). Items are scored on a 3-point scale (none, some, a lot). Total scores are calculated by summing all items. The CASI has shown good internal consistency $(\mathrm{a}=.87)$ and adequate test-retest reliability (range $=.62-.78$ over 2 weeks) (25). The CASI demonstrates strong correlations with measures of trait anxiety (r's $=.55-.69)$ but also explains unique variance in fear that cannot be attributed to trait anxiety measures.

\section{Data analysis}

Independent samples t-tests for continuous data and chi-square tests for categorical data were used to examine differences between boys and girls on the following: age, motherreported FDI, mother reported CSI, mother and child reported pain intensity, child reported CDI and CASI. Pearson product moment correlations were conducted between maternal and child pain and psychological variables separately for sons versus daughters in order to examine sex-specific relationships. 


\section{Procedures: Qualitative interviews}

Children in the qualitative sample were recruited from the same clinic population at the time the initial clinic appointment was made 26 . If the family were willing to participate in the study, they were contacted at home by a trained graduate student interviewer who obtained consent and conducted interviews with parent and child. This qualitative sample consisted of 34 children, 19 girls (56\%) and 15 (44\%) boys, with an age range from 10 to 17 years (mean 13.42). The majority of children were Caucasian (71\%), although Hispanic (18\%), AfricanAmerican (6\%), and mixed-race children (6\%) were also included. At the time of clinic intake, this group of children had experienced pain symptoms for a mean of 36 months. There were no significant differences between the qualitative subsample and the larger quantitative sample for any of the demographic, pain or psychological functioning parameters. The qualitative sample was the largest number obtainable from the larger population within the study period.

Each child and mother (32 pairs) participated in a 60-90 minute, semi-structured life history interview at home prior to their first clinic visit. The interviews were generally conducted in separate rooms to reduce cross-contamination between parents and children. The interviewers were instructed to maintain a friendly, encouraging, but noncommittal demeanor. To elicit the narrative, they used a standard set of open-ended questions and probes to guide the conversation, while encouraging each respondent to talk openly and develop his or her own train of thought. Interviews were both audio- and videotaped. Each set of interviews was identified by a study code number and a pseudonym to ensure confidentiality. The interviews were transcribed by an experienced transcriptionist, and reviewed against the video- and audiotapes for accuracy. All procedures were approved by the University's Institutional Review Board.

\section{Data analysis}

Transcripts were coded by the interviewers using QSR N*6 and were comparatively analyzed for thematic content, using a grounded theory approach. Each interview was read multiple times. Coding categories and comparative themes were developed from the interview content. Each theme identified was queried against the remaining interviews in the database, using a constant comparative method, and subthemes were combined under more generalized thematic headings. Parental and child interviews were compared to ensure that each data item or theme was supported by both respondents for a given dyad.

For this analysis, the following coding categories and themes were selected for comparative study: the parent-child relationship was examined for "closeness," which was assessed by descriptive statements and by the time spent with the parent, openness in talking to the parent, and number and type of activities shared with the parent. Evidence of children modeling their parent's health behavior was also examined. Two aspects of pain-related parent behaviors examined were solicitousness and being critical or minimizing the child's pain (27). "Solicitousness" included parental behaviors that were over-protective or rewarded the child's pain behavior, including exemption from school and chores, providing extra attention and pain paraphernalia including washcloths and ice packs. Being "critical" included attempts to minimize the pain or believing the child was malingering. "Autonomy' was assessed and defined as the child's ability to regulate his or her own behavior 28 . Evidence of maternal behavior - whether the mother internalized her worry, while she tried to remain stoic or externalized her feelings, exhibiting her anxiety to the child - was also analyzed. 


\section{RESULTS}

At the time of clinic intake, children had experienced pain symptoms for a mean of 36 months $(\mathrm{sd}=39.17)$. As shown in table 1 , there were significant differences between boys and girls on pain and functioning variables. Girls demonstrated higher VAS pain intensity scores compared to boys' scores and girls reported higher anxiety sensitivity (CASI) scores than that of boys. Levene's test for equality of variance indicated no significant differences in the variance of boys' and girls' scores despite the presence of more girls than boys in the sample.

The most common child pain conditions included headaches (46\%), myofascial pain (38\%), functional neurovisceral pain disorders including abdominal pain (37\%), fibromyalgia (10\%) and complex regional pain syndrome $(6 \%) ; 23 \%$ of children had multiple pain diagnoses. There was a sex difference for fibromyalgia $(\mathrm{X} 2=4.19, \mathrm{p}<.05)$, with girls significantly more likely to experience this condition than boys. Maternal pain locations included head $(n=42)$, back $(n=40)$, fibromyalgia or widespread bodily pain $(n=29)$, arm/ leg $(\mathrm{n}=21)$, abdominal pain $(\mathrm{n}=6)$ and other $(\mathrm{n}=12)$. Paternal pain locations included back $(\mathrm{n}=35)$, head $(\mathrm{n}=18)$, arm/leg $(\mathrm{n}=18)$, fibromyalgia or widespread bodily pain $(\mathrm{n}=11)$, abdominal pain $(\mathrm{n}=5)$ and other $(\mathrm{n}=19)$. Mothers did not complete pain data for $20 \%$ of fathers $(n=36)$.

\section{Parent-child pain relationships: Quantitative data}

The overlap between parent and child pain was examined separately for boys versus girls, and results are illustrated in figure 1. In terms of the mother-child pain relationship, $62 \%$ of mothers of girls reported experiencing pain compared to $47 \%$ of mothers of boys. Although the findings evidence a trend for mothers of girls to be more likely to experience pain than are mothers of boys, this difference was not significant $(\mathrm{X} 2=3.05, \mathrm{p}=.08)$. In contrast, $58 \%$ of boys had fathers with pain compared to $38 \%$ of girls, a statistically significant difference $(\mathrm{X} 2=3.74, \mathrm{p}=.03)$.

Next, mother-daughter versus mother-son pain relationships were examined for concordance in the location of pain. Information about pain locations was collected differently for children and mothers; headaches and widespread body pain were the only pain locations that could be compared between children and mothers. Thus, the number of daughters with headache who had mothers with headache was compared to sons with headache who had mothers with headache. Similarly, the number of daughters with widespread body pain who had mothers with similar pain was compared to boys with widespread body pain who had mothers with similar pain. The results are illustrated in figure 2. Among children with headaches, girls were more likely to have mothers with headaches (43\%) vs. boys (19\%) $(\mathrm{X} 2=3.84, \mathrm{p}<.05)$. For children with widespread bodily pain (myofascial and/or fibromyalgia pain) more girls (35\%) than boys $(16 \%)$ had mothers with bodily pain, a trend that was not statistically significant $(\mathrm{X} 2=2.51, \mathrm{p}=.11)$. The findings suggest a sex-specific concordance rate between maternal and daughter incidence of chronic head pain that is higher than for sons and mothers. Due to the high rate of missing father data, pain specific analyses were not carried out for paternal pain.

Correlations between maternal and child pain and functioning variables revealed a number of significant mother-daughter associations. In contrast, few significant associations were evident for mother-son relationships. As shown in table 2, maternal depression was correlated with daughters' functional disability, somatization, depression, anxiety sensitivity, and pain intensity. Maternal anxiety was related to all of these daughter variables except for daughters' anxiety sensitivity; maternal somatization was related to all the daughter variables except for daughters' anxiety sensitivity and depression. Maternal anxiety 
sensitivity was only related to parent-reported pain intensity in daughters. As shown in table 3 , the only significant mother-son association to emerge was for maternal anxiety sensitivity and son anxiety sensitivity $(\mathrm{r}=.53, \mathrm{p}<.05)$. The sex-specific correlations show consistent associations between maternal psychological functioning and daughter pain and psychological functioning, while the only relationship for mothers and sons was for anxiety sensitivity.

\section{Parent-child relationships: Qualitative data}

Closeness of relationships-An apparent sex difference emerged in the closeness of parent-child relationships and the satisfaction of mothers and children with these relationships. Nearly all children reported high levels of interaction with their mothers and involvement of the mothers with management of their pain and health care. However, girls reported seeking substantially more emotional and behavioral support from mothers than did boys. Virtually all the girls described themselves as "close" to their mothers, spending a lot of time with them, shopping or cooking, and helping with a work project; only four boys described themselves as close to their mothers. For example, one girl described her day-today relationship with her mother:

I usually talk to my mom... We always play games together. She's always the one who takes me out when we go out, which is nice. Yeah, I mean -- and we watch TV together. I'll help her cook. We do everything together.

Mothers corroborated the high degree of intimacy that daughters sought; with some commenting that their relationship became closer since the pain, including this mother of a 16-year old girl: She went from being an extremely independent kid to being very clinging, very -- not separation anxiety but constantly wanting my attention. And you can't blame her for that given what she was going through. It was just such a shift from -- it was just a very big change.

A number of mothers appeared concerned about this increasing dependence: She's like a two-year-old. She needs Mommy all the time. Because she wants me to fix it. Another mother described her daughter's dependence as a possible social barrier: Emotionally, you know she stays very close to home. She's very scared to- I mean she doesn't do things like go to camp. She doesn't do things like spend the night out. She's completely scared when it comes to flying the coop. It's just developmentally I see her being young for her age in that way.

Mothers may have had cause for concern as over-reliance upon parents to take care of social needs meant that many girls did not develop interactions outside the home. Over-reliance upon mothers included displays of affection that reverted to younger developmental stages, such as wanting to sit on the mother's lap, cuddle and sleep in the same bed or room as the mother and needing to be physically close to her. In many cases, mothers were the exclusive role models, friends and source of support. A highly enmeshed mother-daughter relationship was actually seen as contributing to pain by this 12-year old girl: When I see my mom isn't happy I'm not happy, and until my mom's happy I feel sad. The more she is sad, the more I am and sometimes it could affect the way-how my head hurts.

Although the additional closeness borne from pain was not always welcomed by mothers, they rarely discouraged it. A sense of helplessness to alleviate their child's pain was common, and permitting or even encouraging a high level of inter-dependence may have been one source of comfort that mothers felt confident they could provide. As one mother expressed: 'let me love you through it.' 
In contrast, mothers of boys did not express reservations about their son's increased ties due to the pain. Many mothers readily took on the role of their sons' nurse, with few reporting impositions on their time and most willing to go to great lengths to take the pain away. This included wishing the pain upon themselves, or as this mother reported: I wish I could climb inside of his body and feel what he's feeling so that I could better help him figure it out.

As discussed below, overly concerned mothers of sons often engaged in solicitous behaviors that may have inadvertently rewarded the pain and contributed to boys' disability. Many mothers treated their sons with pain differently to their other children, leading to perceived favoritism. One mother of a 12-year-old boy became heavily involved in her child's life, leaving little time for his siblings: and I suppose you know no doubt he gets far more attention than the other kids.

Some younger boys expressed a similar level of dependence on their mothers as girls when it came to dealing with pain-related tasks. However, this closeness was distinct from girls in that it generally did not extend to sharing hobbies and non-pain tasks. In addition, many older adolescent boys attempted to pull away from their mothers' displays of care, concern and affection. This marked a striking sex difference in how boys versus girls responded to mother-child relationships. While girls of all ages seemed to enjoy the closeness, older boys often expressed a desire for independence or for their mothers not to worry so much about them.

The following quote from a 17-year old male demonstrates a desire for independence including when arguing with other family members:

Yeah, I tell her all the time (not to defend him). Some times I'll push her away. Not like push her, but just like you know (tell her to back off). He went on to describe his mother as 'paranoid' about his pain and heath. His mother recognized these concerns; however it was almost as though her son's desire for space fueled her efforts to control: Sometimes he get a little frustrated with me because I'm a very paranoid mom. I'm terrified of something happening to my kids. So that's when we have a little bit of problem because he's- out of the 3, he's my daring one. He's very independent so.

Many mothers of boys were unwilling to relinquish their ties, even though they may have recognized the disadvantages of being overly involved: The one thing is, maybe because I am so nurturing, maybe I do need to back off a little bit. Maybe I'm not doing the right thing for him. Although I don't know how much further I can back off because I want him still in my life.

The lack of father interviews made it difficult to gauge the closeness of relationships with fathers. However, some interviews with mothers and children gleaned information about the father's role. Four fathers were highly involved with the child and the pain problem; however, most fathers were reported as not aware or as getting all their information from mothers. Most of these fathers were also described as having low levels of interaction with the children, either because they "work all the time" or because of divorce or separation.

\section{Pain models}

One way that fathers may have played a role in parent-child pain relationships was by serving as models for pain behavior. Although few girls discussed pain in their fathers, a number of boys reported this as significant for them. One example included a 12-year old boy with back pain, who reported his father experienced similar pain: 
In a way, we help each other. We know what it feels like and so more than anybody else really in our family. We know and so uh we know what the other person's going through.

Similarly, mothers were often pain models for their daughters. A majority of mothers with daughters either reported they experienced on-going pain, or their daughters reported their mothers had pain. Although most mothers didn't make a connection between their own pain and health and their daughter's pain behavior, a number did: Melissa knows I have headache- and I would lie down with a washcloth on my head. Melissa would come in when she was six years old and tell me she had a headache and she would get herself a washcloth and lie next to me. This child's headaches had escalated to the point that she would now break down in a crying 'hysteria' when she experienced head pain.

\section{Pain-related parenting}

Solicitousness-For both boys and girls reporting pain, many mothers regularly encouraged passivity, and near-daily reliance upon the parents to facilitate rest, suggest distractions, and provide comfort measures such as massage or ice packs. Maternal overprotection was also evident, with many mothers carefully monitoring their children's symptoms and controlling the child's own management strategies. Most fathers were not described as deeply involved with their children and, where they were involved or concerned, as supporting the same type of behavior as the mothers.

Parental solicitousness and over-protection emerged as a differential, in that the parents of boys - either mothers acting alone or mothers with fathers' support - were more likely to use protective and reinforcing strategies when dealing with their child's pain than were mothers of girls. In fact, the majority of mothers of sons allowed or encouraged their sons to rest, stay home from school, and rely on them for help. One mother went to the extent of holding the cup to her son's lips when he wanted to drink and holding the telephone to his ear when he made calls. Some parents encouraged solicitousness by creating a nestlike environment, as one 16-year-old boy told the interviewer: My mom likes to ask me where I want to be to be comfortable[and] get me comfortable. My dad will say I'll go out and get you a movie to watch or food or anything.

The mother of a 14-year-old boy answered, when asked what was the most helpful thing she did for her son:

I think I just give him moral support. And the (mommy) comfort. I'll try to rub his head, I'll give him a hug, or something. When asked about the daily school decision, she said, I made those decisions. In the morning. There were days when I would force him, and we'd get all the way to the car and he would just cry. He can't make it. His head hurts too much- so he would come back into the house.

Another mother described the impact of her over-protectiveness on her son's normative development:

I think we've become overly protective of him and he's not had a chance to do some of the things kids his age have normally done because we worry too much which probably causes him to have a headache or something

Several parents, particularly parents of girls, were less protective and encouraged the child to "get going," "deal with it," and "work through the pain." Thus, mothers of daughters were more likely to take a "tough love" approach to school attendance, by trying to facilitate normal activities - providing a quieter place for homework or a supply of healthy snacks or by helping with self-help approaches, such as the use of yoga poses. 
Encouragement of functioning might involve striking a balance between being directive and letting her child to make decisions, as described here by the mother of a 13-year-old girl:

She needs to make her own decisions. And I understand that I need to pull back and not impose myself on her. And that's fine. But then at some point you have to still be a parent, and you have a child who's -- everybody has a kid that they don't want to go to school for one reason or another.

\section{Being critical}

In a few cases, parents were described as negative, not believing in the child's pain or not treating it seriously. Some parents even questioned whether their child was malingering. Generally, boys were more likely to report attempts to minimize their pain. One boy felt that he had to exaggerate his pain around several of his relatives so they would believe in his pain: It's like they were watching my every move, and it just - it's annoying that I now have to act like I'm in more pain than I am in around them just to make them be quiet about it. This boy went on to describe how his uncle had repeatedly told him to 'toughen up.'

Although data regarding fathers' parenting strategies are less detailed than mothers, it appeared that fathers were more likely to be critical of or dismiss their children's pain. Critical or questioning behavior was most likely to be perceived by both boys and mothers as coming from fathers or other male relatives. For example, one mother of a 16-year-old boy, who was separated from her husband, reported:

And going to see his dad, he doesn't particularly -- he has a problem with that. His father doesn't understand. He thinks he just doesn't want to do anything and wants to lay around the house.

\section{Child autonomy}

As a result of pain-parenting strategies that restricted children's independence, children's autonomy or ability to self-regulate behavior was often affected. For girls, emotional autonomy was particularly compromised. An overly enmeshed mother-daughter relationship meant that many girls came to rely on their mothers for emotional support, often to the detriment of establishing their own peer networks. For boys, a high level of parental solicitousness and over-protection often interfered with their ability to engage in independent tasks. For both boys and girls, dependence on parents to take care of painrelated tasks, including pain reducing strategies was common and may have increased painrelated disability. Some children wished it was otherwise:

I wish that my parents would not...sometimes they're just like too helpful, and it's just like, "I can do that." I'm capable of doing that, so I love them being helpful, but too helpful just gets me - uncomfortable.

Limited autonomy meant that many children displayed low self-efficacy - that is - limited confidence in their ability to perform activities. Reduced self-efficacy extended to school, peer relationships and other daily activities but was most often the case with painmanagement tasks, such as expressed by this 13 -year-old girl:

I don't care who knows what to do. If I could just do something to stop it, I would do it. But I don't know what to do either. Some parents were aware that their child's dependence meant a limited sense of competence: Because of all the things she's been through she has all these problems with separation from me so I'm trying to get her a little more independent so I'm hoping she can learn ways to make herself feel better on her own. 
Children appeared to take on board the messages they received from their mothers about how to respond to pain and symptom management. Where mothers supported autonomy, both girls and boys were more likely to attend school regularly, use distraction, and continue most activities; where mothers encouraged passive or dependent behavior, children coped with pain primarily by staying home and resting or sleeping. The high level of concordance between behavior encouraged and behavior adopted by children demonstrates that boys and girls with chronic pain are highly receptive to the messages generated by their parents regarding appropriate behaviors.

\section{Mothers' behaviors reflected}

In exploring some of the possible reasons for the use of different parenting strategies in dealing with sons versus daughters, it was apparent that differences existed in how mothers handled their own concerns or anxieties about the child's pain. The majority of mothers who tended towards solicitousness in their sons were 'worriers' and projected a high degree of anxiety and felt overwhelmed by themselves and by their sons. In this sense, mothers of boys tended to 'externalize' their concern.

One mother of an 11-year-old boy described the multiple ways she expressed her feelings:

Awful. I think I cry when he's not around so he doesn't know that I'm upset. I try and do that. I pray a lot. I call my mom and talk to her. I think a lot. And I don't sleep well at night because I'm thinking, okay, what haven't we done?I wake up in the middle of the night just sick to my stomach. This mom treated her son like an invalid, and stayed at home with him (she's just always there). Both this boy's parents had had painful accidents, which he described as frightening. As his own pain developed, he became scared that something really bad would happen, and now thinks about it probably all the time- it's the thought of hurting longer. Not only was the mother's freely expressed anxiety conveyed to her son through her constant attentions, he seemed to have taken on her worry about the possible risks of pain, both in the case of his father and himself. Similar patterns were identified in the interviews of several boys whose mothers were over-protective.

In contrast, the majority of mothers of daughters were more likely to keep their worries to themselves, in attempting to be "the good mom." One such mother of a 16-year-olddaughter described herself this way:

Actually, my family is pretty used to me fixing everything. I'm kind of that fix-it person. Mom was the rock, and then I became the rock. This mom had had an "excruciating" pain episode of her own: they've seen me in pain, but I'm the type that I hide it from my kids. I have to put the Mom hat on when the kids are around. Her daughter described her own role in the family: My mom's not home till late- so I do help with my sisters and tell them to take a bath, and take a shower now - I'll fix dinner for my grandpa. I'm here all the time, so I fix breakfast and lunch for my grandpa- and I'm more than happy to do it for them. This daughter both modeled her mother's behavior and internalized the message that she should "deal with it." She also wished her mother would do more to help her.

Although all mothers expressed similar concerns about their child's pain, mothers of daughters were more likely to put on a brave face. Accordingly, girls may model their mothers in trying to play "the perfect daughter," as well as in modeling the mother's demonstrations of pain. In contrast, boys may have greater exposure to their mothers' external manifestations of worry. 


\section{DISCUSSION}

A mixed-method approach was used to understand the relationship between parental behavior and children's chronic pain. The data support our hypothesis regarding sex-specific parent-child pain relationships. The quantitative findings showed that maternal reports of pain and psychological functioning were significantly correlated with daughters' pain and psychological functioning; moreover, daughters appear susceptible to developing pain in similar sites as their mothers. The relationship between maternal and son characteristics was less apparent. Only maternal anxiety sensitivity was correlated with son anxiety sensitivity. A relatively high percentage of boys had fathers with pain suggesting sons' pain may mirror fathers' pain. The qualitative findings lend insight into these sex-specific relationships and suggest that the chronicity of pain and impairment are mediated by different social learning and family factors for boys versus girls.

The quantitative data are consistent with our previous research showing stronger relationships between mother-daughter than mother-son pain sensitivity for healthy children's laboratory and bodily reports of pain (12). The present study extends this relationship to children with chronic pain. However, our findings are at odds with previous research showing a pathway from parental anxiety sensitivity to healthy children's laboratory pain for girls only (29). In the present study, mother-son pain correlations were non-significant apart from anxiety sensitivity. One explanation lies in literature showing the importance of environmental factors in male anxiety sensitivity (30). The outward displays of worry evidenced by mothers of boys in the qualitative data may provide an environmental influence for anxiety sensitivity in boys with chronic pain. Taken together, our findings point to different models for parental influences on healthy children's responses to acute pain versus parental influences on children's chronic pain.

\section{Exploring mechanisms qualitatively}

The qualitative findings build upon the sex-differences seen in the quantitative data and suggest two distinct hypothetical pathways underlying the development of pain chronicity in adolescent girls and boys.

\section{The mother-daughter pathway}

An overly enmeshed mother-daughter relationship provides an opportunity for girls to readily model their mothers' behaviors, including pain behavior and psychological functioning, consistent with associations seen in the quantitative data. Although mothers may feel uncomfortable with their daughter's burgeoning needs and are willing to encourage better functioning, they also facilitate over-closeness, perhaps due to frustration with limited pain-relief options. Resultantly, girls seem to meld their own self-identity with that of their mothers. Given that a key challenge of adolescence is the development of autonomy and identity $(31,32)$, moving closer towards their mothers during these years may interfere with girls' establishment of peer networks and a sense of self as connected yet separate from the family. In fact, recent work has found an association between the closeness of the parentchild relationship and increased levels of pain in adolescents with chronic pain (33). An enmeshed parent-child relationship may present not only disruptions to normative developmental processes, but also increase disability by compromising functioning despite pain. If the mother has taken on the family role of the person who "fixes everything," then the daughter might learn, through modeling and family reinforcement, to set similarly high standards for herself. Maintaining such a role would likely promote ongoing stress and recurrent pain. 


\section{Pathways for boys}

In boys, mothers with high levels of worry and anxiety sensitivity endeavor to promote continuing dependence and passivity in sons, particularly as the son enters adolescence and shows signs of pulling away from the family. If the father is absent or ill, the mother's anxiety to keep her son close is probably heightened, while the son lacks the strong samesex parental model that would reinforce his transition from dependent child to maturing adolescent. Even an absent father might act as a model, suggesting that inability to function brings freedom from responsibility. Fathers with health issues are salient models to boys, who may not be able to share typical activities due to reduced functioning, but who can share pain. In some families, boys learn to recognize -either accurately or through a sensitivity to definitions of male tasks - critical attitudes in their fathers and other male relatives toward their dependency and disability. In other families, fathers appear to support the reinforcing strategies favored by mothers.

Paternal pain or disability coupled with maternal worry seems to demonstrate to sons that the persistence of symptoms will be rewarded with comforts, lowered expectations, and even material gifts like video games. Our findings are in accord with previous work demonstrating that parents of boys are more likely to endorse items reflecting solicitous behavior than are parents of girls; and mothers are more likely than fathers to endorse solicitous behaviors (34). By providing such rewards, mothers seem to gain the assurance of comfort and closeness that they desire. Nevertheless, the pain appears to promote continued anxiety in the mother and increasing levels of worry and pain in the son, setting up an ongoing cycle of pain, reinforcement, and anxiety. As boys enter late adolescence, they apparently recognize the dysfunction associated with excessive dependence and turn away from maternal efforts of comfort and care, a further cause of worry for their mothers.

For all children, but especially for boys, mothers' expectations or behaviors did not appear to vary across development. Thus, mothers used the same kind of behavior - encouraging dependence and limiting self-efficacy - regardless of their sons' age. Extending early parenting practices to adolescence, when ideally children pursue activities and friendships outside the home while maintaining supportive relationships at home28, is often developmentally insensitive. A key parenting challenge involves negotiating a balance between previously effective strategies and new more appropriate strategies as children mature (35). However, confusion regarding how best to parent a child with chronic pain is common (36). It is likely that chronic pain presents a number of barriers to children's healthy development, not least through its impact upon normative parenting practices. By continuing the same degree of control or even increasing solicitousness and protection, parents might be inadvertently suspending their adolescent's development, including autonomy and self-efficacy, and preventing a smooth transition to adulthood.

The symmetry between the level of autonomy encouraged by mothers and that adopted by children points to additional disruptions in developmental norms. Both boys and girls in the study showed behavior that was surprisingly consistent with the degree of passivity encouraged by mothers. Assertion is expected as adolescents and parents negotiate their way from parent-directed authority to adolescent autonomy (37). However, reports of parentchild dialogue were largely absent from the interviews. Our findings are consistent with the wider literature showing an excessive level of parental control and passivity in children with chronic health issues illnesses $(38,39)$. The literature suggests poor outcomes for such adolescent with recent findings linking lower levels of adolescent autonomy to higher functional impairment (40). 


\section{CONCLUSIONS}

Parent-child pain relationships likely exist due to social learning of pain behaviors and to family dynamics (41). Together, the quantitative and qualitative findings support both explanations. Consistent with previous research $(42,43)$, our data point to the likelihood of children learning pain responses from their parents. The data are supportive of sex-specific modeling with girls being sensitive to maternal pain models and boys to their fathers. A broad social learning view (43-46) encompassing vicarious learning, modeling, and reinforcement may operate in these families. The qualitative data highlight the importance of family dynamics, including disruptions to normative parenting practices and barriers to children's autonomy and self efficacy. These data support distinct parent-child trajectories leading to impairment in boys versus in girls. An overly close mother-daughter relationship seems to present barriers to girls' identity development, autonomy and self-efficacy. Mothers of boys may be involved in the child's pain by being overly anxious or 'fussy,' creating a preponderance of perceived stress in the family and lowered self-efficacy in boys as they face adolescence with a desire for autonomy but limited resources to negotiate this. Boys also seem sensitive to the expectations of other males, who possibly view boys' pain and excessive maternal attention as at odds with male norms.

This study represents a preliminary step towards understanding the impact of fathers in parent-child pain relationships. Fathers are largely absent in studies of parental influences in children's chronic pain even though it is now recognized that high levels of paternal psychopathology provide a risk for child psychopathology $(47,48)$.

A number of limitations preclude strong conclusions from the findings. We are unable to determine whether parental responses develop from children's pain, or whether parental behavior precedes and indeed leads to child exacerbated pain and disability. Consistent with a bilateral model (35), it is likely that each family member affects the other in a complex, transactional manner. Other limitations include the lack of reports from fathers about their own pain and functioning characteristics and limited data on the type and chronicity of parental pain. It is also possible that genetic factors play a part in the family transmission of pain, and further research should investigate the interplay between social learning, family dynamic and biological components of parental influences in children's pain.

Despite these limitations, this study indicates that there are marked differences in the family processes through which functional pain becomes chronic and disabling in adolescent boys and girls. The findings also highlight the importance of using mixed methodology to explore a novel and vast area such as parent-child interactions in the context of chronic pain. The interviews not only confirmed but also clarified and refined the sex-specific relationships revealed in the quantitative data to suggest two distinct, hypothetical pathways for girls versus boys. Our pathways merit systematic exploration in a multi-method study which applies quantitative and qualitative methods to analyze the specific differences here described. If these pathways are borne out by further investigation, they suggest important implications for differential clinical approaches to chronic pain in adolescents.

\section{Acknowledgments}

This research was supported by NIMH grant R01 MH 063779 and by a seed grant from the Mayday Fund.

\section{REFERENCES}

1. Schanberg LE, Anthony KK, Gil KM, Lefebvre JC, Kredich DW, Macharoni LM. Family pain history predicts child health status in children with chronic rheumatic disease. Pediatrics. 2001; 108(3):E47. [PubMed: 11533365] 
2. Laurell K, Larsson B, Eeg-Olofsson O. Headache in schoolchildren: association with other pain, family history and psychosocial factors. Pain. 2005; 119(1-3):150-158. [PubMed: 16298064]

3. Kroner-Herwig B, Heinrich M, Morris L. Headache in German children and adolescents: a population-based epidemiological study. Cephalalgia. 2007; 27(6):519-527. [PubMed: 17598791]

4. Aromaa M, Rautava P, Helenius H, Silanpaa ML. Factors of early life as predictors of headache in children at school entry. Headache. 1998; 38:23-30. [PubMed: 9504999]

5. Evans S, Keenan TR, Shipton EA. Psychosocial adjustment and physical health of children living with maternal chronic pain. J Paediatr Child Health. 2007; 43(4):262-270. [PubMed: 17444828]

6. Evans S, Tsao JC, Lu Q, Myers CD, Suresh J, Zelter LK. Parent-child pain relationships from a psychosocial perspective: A review of the literature. J Pain Manage. 2008; 1(3):237-246.

7. Palermo TM, Chambers CT. Parent and family factors in pediatric chronic pain and disability: an integrative approach. Pain. 2005; 119(1-3):1-4. [PubMed: 16298492]

8. Schanberg LE, Keefe FJ, Lefebvre JC, Kredich DW, Gil KM. Social context of pain in children with Juvenile Primary Fibromyalgia Syndrome: parental pain history and family environment. Clin J Pain. 1998; 14(2):107-115. [PubMed: 9647451]

9. Campo JV, Bridge J, Lucas A, et al. Physical and emotional health of mothers of youth with functional abdominal pain. Arch Pediatr Adolesc Med. 2007; 161(2):131-137. [PubMed: 17283297]

10. Chambers CT, Craig KD, Bennett SM. The impact of maternal behavior on children's pain experiences: an experimental analysis. J Pediatr Psychol. 2002; 27(3):293-301. [PubMed: 11909936]

11. Fillingim RB, Edwards RR, Powell T. Sex-dependent effects of reported familial pain history on recent pain complaints and experimental pain responses. Pain. 2000; 86(1-2):87-94. [PubMed: 10779665]

12. Evans S, Tsao JC, Zelter LK. Relationship of child perceptions of maternal pain to children's laboratory and non-laboratory pain. Pain Res Manag. 2008; 13(3):211-218. [PubMed: 18592057]

13. Edwards PW, Zeichner A, Kuczmierczyk AR, Boczkowski J. Familial pain models: the relationship between family history of pain and current pain experience. Pain. 1985; 21(4):379384. [PubMed: 4000687]

14. Barkmann C, Romer G, Watson M, Schulte-Markwort M. Parental physical illness as a risk for psychosocial maladjustment in children and adolescents: epidemiological findings from a national survey in Germany. Psychosomatics. 2007; 48(6):476-481. [PubMed: 18071093]

15. Bursch B, Tsao JC, Meldrum M, Zeltzer LK. Preliminary validation of a self-efficacy scale for child functioning despite chronic pain (child and parent versions). Pain. 2006; 125(1-2):35-42. [PubMed: 16740360]

16. Tsao JC, Meldrum M, Bursch B, Jacob MC, Kim SC, Zeltzer LK. Treatment expectations for CAM interventions in pediatric chronic pain patients and their parents. Evid Based Complement Alternat Med. 2005; 2(4):521-527. [PubMed: 16322810]

17. Garber J, Walker LS, Zeman J. Somatization symptoms in a community sample of children and adolescents: further validation of the children's somatization inventory. Psychol Assess. 1991; 3:588-595.

18. Walker LS, Greene JW. The functional disability inventory: measuring a neglected dimension of child health status. J Pediatr Psychol. 1991; 16(1):39-58. [PubMed: 1826329]

19. Varni JW, Walco GA, Katz ER. Assessment and management of chronic and recurrent pain in children with chronic diseases. Pediatrician. 1989; 16(1-2):56-63. [PubMed: 2657693]

20. Derogatis LR. BSI 18, Brief Symptom Inventory 18: Administration, Scoring and Procedures Manual: NCS Pearson. 2001

21. Reiss S, Peterson RA, Gursky DM, McNally RJ. Anxiety sensitivity, anxiety frequency and the prediction of fearfulness. Behav Res Ther. 1986; 24(1):1-8. [PubMed: 3947307]

22. Maller RG, Reiss S. Anxiety sensitivity in 1984 and panic attacks in 1987. J Anxiety Disord. 1987; 6:241-247.

23. Kovacs M. The efficacy of cognitive and behavior therapies for depression. Am J Psychiatry. 1980; 137(12):1495-1501. [PubMed: 7435704] 
24. Craighead WE, Curry JF, Ilardi SS. Relationship of children's Depression Inventory factors to major depression among adolescents. Psychol Assess. 1995; 7:171-176.

25. Silverman WK, Fleisig B, Rabian, Peterson RA. Child Anxiety Sensitivity Index. J Clin Child Adoles Psychol. 1991; 20:162-168.

26. Meldrum ML, Tsao JC, Zeltzer LK. Just be in pain and just move on: Functioning limitations and strategies in the lives of children with chronic pain. J Pain Manage. 2008; 1(2):131-141.

27. Hermann C, Zohsel K, Hohmeister J, Flor H. Dimensions of pain-related parent behavior: development and psychometric evaluation of a new measure for children and their parents. Pain. 2008; 137(3):689-699. [PubMed: 18534757]

28. Noom MJ, Dekovic M, Meeus WH. Autonomy, attachment and psychosocial adjustment during adolescence: a double-edged sword? J Adolesc. 1999; 22(6):771-783. [PubMed: 10579889]

29. Tsao JC, Lu Q, Myers CD, Kim SC, Turk N, Zeltzer LK. Parent and child anxiety sensitivity: relationship to children's experimental pain responsivity. J Pain. 2006; 7(5):319-326. [PubMed: 16632321]

30. Taylor S, Jang KL, Stewart SH, Stein MB. Etiology of the dimensions of anxiety sensitivity: a behavioral-genetic analysis. J Anxiety Disord. 2008; 22(5):899-914. [PubMed: 18029140]

31. Sessa FM, Steinberg L. Family structure and the development of autonomy during adolescence. J Early Adolesc. 1991; 11(1):38-55.

32. Shapiro, ER. Individual change and family development: Individuation as a family process. In: Falicov, CJ., editor. Family transitions: Continuity and change over the life cycle. New York: Guilford; 1988. p. 159-180.

33. Logan DE, Guite JW, Sherry DD, Rose JB. Adolescent-parent relationships in the context of adolescent chronic pain conditions. Clin J Pain. 2006; 22(6):576-583. [PubMed: 16788346]

34. Huguet A, Miro J, Nieto R. The inventory of parent/caregiver responses to the children's pain experience (IRPEDNA): development and preliminary validation. Pain. 2008; 134(1-2):128-139. [PubMed: 17509763]

35. Kuczynski, L. Handbook of dynamics in parent-child relations. Thousand Oaks, CA: Sage; 2002.

36. Jordan AL, Eccleston C, Osborn M. Being a parent of the adolescent with complex chronic pain: an interpretative phenomenological analysis. Eur J Pain. 2007; 11(1):49-56. [PubMed: 16458550]

37. Sillars A, Koerner A, Fitzpatrick MA. Communication and understanding in parent-adolescent relationships. Hum Commun Res. 2005; 31:102-128.

38. Coakley RM, Holmbeck GN, Friedman D, Greenley RN, Thill AW. A longitudinal study of pubertal timing, parent-child conflict, and cohesion in families of young adolescents with spina bifida. J Pediatr Psychol. 2002; 27(5):461-473. [PubMed: 12058010]

39. Hanna KM, Guthrie D. Adolescents' behavioral autonomy related to diabetes management and adolescent activities/rules. Diabetes Educ. 2003; 29(2):283-291. [PubMed: 12728755]

40. Palermo TM, Putnam J, Armstrong G, Daily S. Adolescent autonomy and family functioning are associated with headache-related disability. Clin J Pain. 2007; 23(5):458-465. [PubMed: 17515745]

41. Saunders K, Korff MV, Leresche L, Mancl L. Relationship of common pain conditions in mothers and children. Clin J Pain. 2007; 23(3):204-213. [PubMed: 17314578]

42. Craig, KD. Social modeling influences: Pain in context. In: Sternbach, RA., editor. The psychology of pain. 2nd ed. New York: Raven; 1986.

43. Walker LS, Claar RL, Garber J. Social consequences of children's pain: when do they encourage symptom maintenance? J Pediatr Psychol. 2002; 27(8):689-698. [PubMed: 12403859]

44. Bandura, A. Social foundations of thought and action: A social cognitive theory. Englewood Cliffs, NJ: Prentice-Hall; 1986.

45. Craig, KD. Social modeling influences: Pain in context. In: Sternbach, RA., editor. The psychology of pain. 2nd ed.. New York: Raven; 1986. p. 67-95.

46. Mischel, W. A social-learning view of sex differences in behaviour. In: Maccoby, EE., editor. The development of sex differences. Stanford, CA: Stanford Univ Press; 1966. p. 56-81. 
47. Ramchandani PG, Stein A, O'Connor TG, Heron J, Murray L, Evans J. Depression in men in the postnatal period and later child psychopathology: a population cohort study. J Am Acad Child Adolesc Psychiatry. 2008; 47(4):390-398. [PubMed: 18388761]

48. Bogels S, Phares V. Fathers' role in the etiology, prevention and treatment of child anxiety: a review and new model. Clin Psychol Rev. 2008; 28(4):539-558. [PubMed: 17854963] 


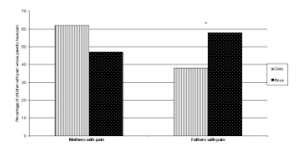

Figure 1.

Mother-child and father-child pain overlap for boys versus girls 


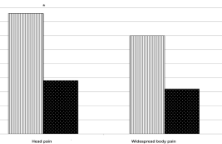

Figure 2.

Mother-child pain overlap for specific pain conditions for boys versus girls 


\section{Table 1}

Means and standard deviations for child and mother pain and functioning variables by child sex

\begin{tabular}{|l|l|l|}
\hline Child variables & $\begin{array}{l}\text { Girls } \\
\mathbf{n = 1 2 8}\end{array}$ & $\begin{array}{l}\text { Boys } \\
\mathbf{n = 5 1}\end{array}$ \\
\hline Age in years & $14.39(2.57)$ & $14.24(2.51)$ \\
\hline FDI parent report & $22.42(13.06)$ & $18.13(12.01)$ \\
\hline CSI parent report & $28.05(18.30)$ & $25.52(17.52)$ \\
\hline $\begin{array}{l}\text { Pain Intensity (VAS) child report } \\
\text { parent report }\end{array}$ & $5.51(2.90)$ & $3.73(2.88)$ \\
\hline CDI T score & $53.69)^{*}$ \\
\hline CASI & $29.01(7.0)$ & $26.68(6.32)^{*}$ \\
\hline Maternal variables & & $50.60(8.74)$ \\
\hline $\begin{array}{l}\text { SCL-90 Somatization } \\
\text { Depression } \\
\text { Anxiety }\end{array}$ & $7.69(7.21$ & $7.90(7.10)$ \\
\hline Maternal ASI & $3.68(5.50)$ & $9.12(9.72)$ \\
\hline Mother pain (yes/no) & $13.20(11.75)$ & $14.81(10.80)$ \\
\hline Father pain (yes/no) & $75(62 \%)$ & $24(47 \%)$ \\
\hline
\end{tabular}

* ${ }^{*}<.05$

FDI: Functional Disability Index; CSI: Child Somatization Inventory; CDI: Child Depression Inventory; CASI: Child Anxiety Sensitivity Index; ASI: Anxiety Sensitivity Index 


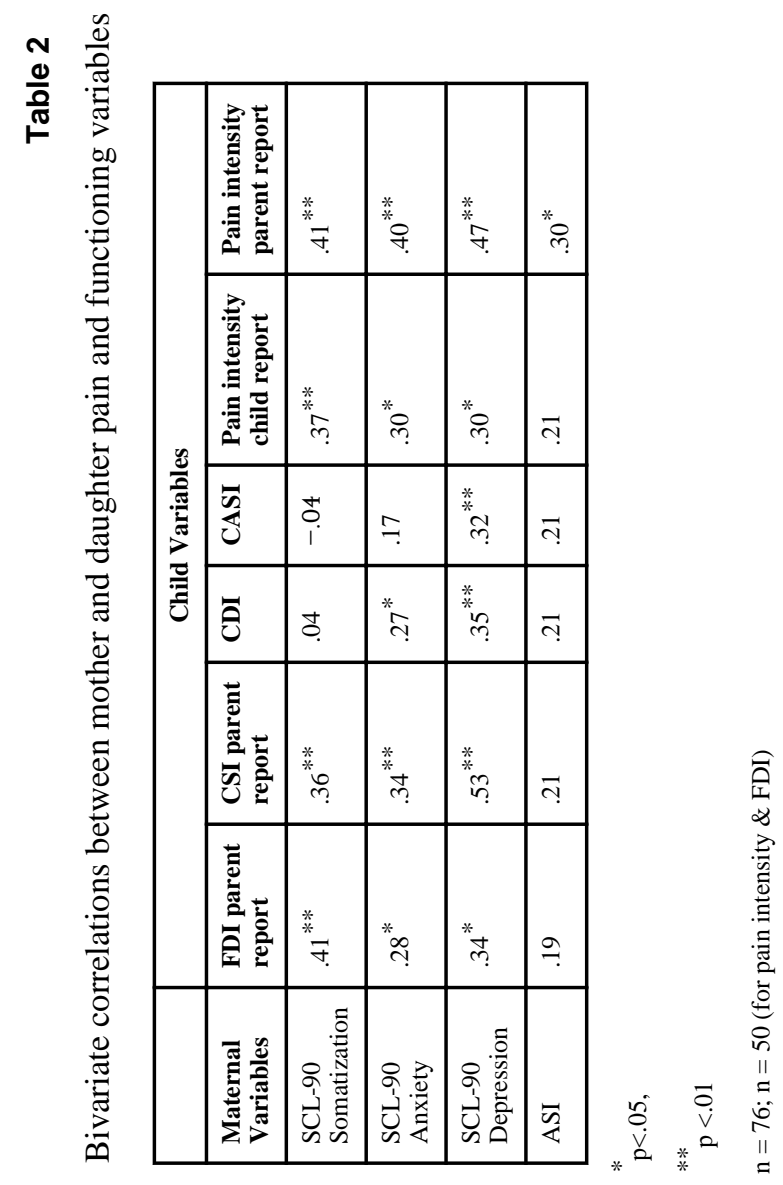

Int J Disabil Hum Dev. Author manuscript; available in PMC 2011 November 1. 


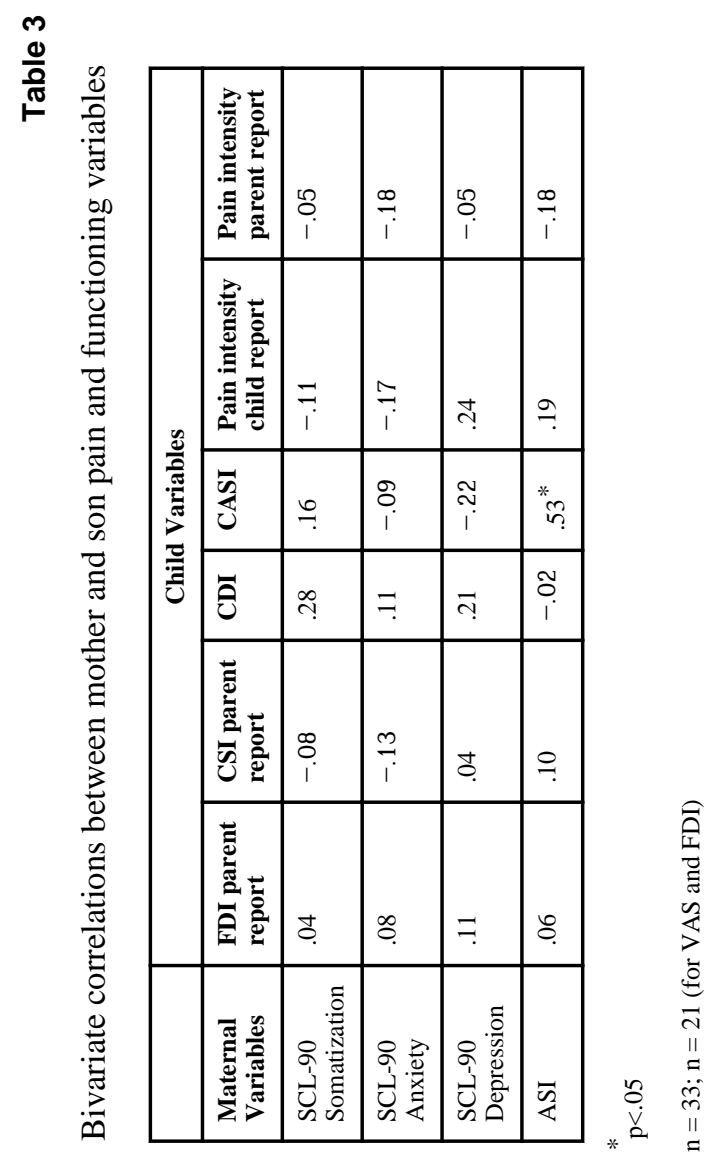

Int J Disabil Hum Dev. Author manuscript; available in PMC 2011 November 1. 